\title{
How to apply politically correct lexicon in English classroom
}

\author{
Alla Bolshak $^{1}$ and Karina Voloshina ${ }^{1, *}$ \\ ${ }^{1}$ Kuban state University, 149 Stavropol str., 350040 Krasnodar, Russia
}

\begin{abstract}
The article describes some approaches to explaining the essences of politically correct lexicon in English language classes. The purpose of this work is not only to familiarize learners with the concept of "political correctness", but also to present alternate opinions on this subject so they can determine their own position with this issue in the future. The analysis of a series of papers on political, social and cultural aspects which influence interpersonal relationships allowed us to identify four major groups of politically correct lexical units which should be considered when communicating with members of different cultural backgrounds: 1) words used to reduce discriminatory practices; 2) words used for delicate description of people different from others in physiological and psychological parameters; 3 ) words used for tactful description of people with low social-economic status; 4) words used for diplomatic description of activities undertaken by government bodies. However it should be stressed that political correctness and good manners are not at all interchangeable concepts, and teachers ought to pass on this idea to their students.
\end{abstract}

\section{Introduction}

The purpose of this work is to describe a number of approaches to the interpretation of so-called politically correct lexicon, which is quite common in modern English textbooks. We considered it appropriate to address this subject, because now, in the age of globalization, all types of international contacts have become a standard practice, but, as we know, for their full implementation a person must clearly understand the mentality of those people who he/she needs to communicate with. Ideally, political correctness is the characteristics, which each society member should possess. It covers absolutely all areas of our life: family and professional interpersonal relationships, relations between members of different social backgrounds and yet relations among nations. However, we have to state that at present we witness human activity dehumanization in many areas, which results in bias and prejudice generation [1], when the cruel treatment of certain groups is perceived as a justifiable response to the violation of the generally accepted rules rather than a problematic situation [2]. Political correctness as an important aspect of communication plays a crucial role in this process since many experts are intended to eradicate inequality in society. It should be noted

\footnotetext{
*Corresponding author: ksvoloshina@icloud.com
} 
that there are the linguists as well as representatives of other academic disciplines who find such tendency farfetched. They believe that the problem lies within us, in our individual attitude towards certain processes taken place in a society rather than in concern to sound undiplomatic, calling things what they are.

\section{Research material and methods}

The study we conducted was illustrated by the examples selected by continuous sampling from newspaper and magazine articles. We strongly believe that when students encounter the cases of politically correct lexicon, their lecturers should not only introduce them to this controversial language phenomenon, giving an integrated description of political correctness as the latest trend in society, but present alternate points of view on this subject. Being aware of the subtleties of perception of a concept by different participants of the communicative process, the Russian-speaking partner will be able to choose the right tactics of communication with their English-speaking interlocutor while having their own opinion. In other words, working with politically correct vocabulary is not just that we give a characteristic to some concept. In our view, this is precisely the case when we can make students think about the reasons for their appearance in the language. Doing this work students can also assess their actual competence in interacting with others from a culturally different community [3]. And finally, teachers can encourage students to reflect on the question why the established lexical unit that designates this or that meaning no longer satisfies modern language norms. We suggest that such approach may contribute to teacher professional development efficiency as well [4].

\section{Discussion}

Practice shows that this issue cannot be approached one-sided: it is necessary to take into consideration all factors that may influence the interpretation of the object of politically correct speech. Therefore, if we come across the examples of such words in the student's book, we discuss the relevance of their use in a particular context and make our arguments in this regard.

It is a well-known fact that main personality traits are often associated with moderate traditional political attitudes [5]. In order to understand the nature of political correctness, it makes sense to familiarize ourselves with some of the definitions of this concept that we have found in various scientific papers on this topic. To begin with, Lorenzo Magnani describes political correctness as a phenomenon which concerns language, policies and actions that are intended to avoid anything that may offend a particular group of people in society [6]. According to Oscar Pérez De La Fuente, political correctness as a social phenomenon is currently of great importance because it changes our views on some cultural values, such as difference, pluralism as well as freedom and neutrality [7]. Valeri Lichev and Miroslava Hristoskova believe that political correctness is based on the ideas of tolerance promoted in the period of West European Enlightenment when the equality of all people and the universality of human nature were declared [8]. Bojana Klepac Pogrmilovic points out that one of the main features of political correctness is linguistic engineering which is meant to influence peoples' life stance and beliefs by eliminating discriminatory language and at the same time keeping to certain linguistic traditions [9].

In line with the problem under consideration, we will provide some opposing opinions about political correctness. So, Alexis Dirakis suggests that political correctness is mainly focused on various forms of a prohibition and can be considered as a moral or even judicial censorship [10], which may cause serious consequences. Ivón Cepeda Mayorga identifies 
political correctness as a concept which highlights a body of principles and norms to follow if we want to set down rules for a specific social behavior that is indicative of a certain community and endorses an ideal identity. But on a par with this opinion, we should be aware of the fact that, on the one hand, such behavioral pattern implies a sense of public recognition by a specific group of population, on the other, it can lead to the situation when the rest of society will have to conform to a mode of life, which are absolutely inconsistent with their understanding of societal concerns [11]. Adam Sikorski emphasizes that one of the problems political correctness touches upon is how we perceive each other and our society on the whole and how not use vocabulary that may conceivably be construed as offensive, discriminatory or pejorative [12]. In respect of modern society where such notions as culture, race, and ethnicity are closely interconnected is a matter of great importance [13]. Even such a brief review of the concept on political correctness shows that there is no consensus on the nature of this phenomenon. As a result, people treat lexical units of this category in different ways expressing their opinions in numerous papers published in various sources. But it seems obvious to us that the linguistic behavior rules cannot be determined only by the ideas that are widely circulated in the media and other sources and sometimes even brought to the level of ideology. We suppose that every person should have his/her own point of view on this problem.

Having analyzed the mentioned above lexical material presented indifferent contexts, we concluded that its cultural, historic, social and linguistic aspects act as an adequate basis. Taking this fact into account, English language learners can be offered a general classification of lexical units we consider. At the same time, we find it important to give (where possible) a counter-argument regarding the proposed interpretation of these words and expressions, thus showing that there is also an alternative position regarding a given lexical formation. The mechanism of the PC lexical unit step-by-step introduction into the classroom activity can be shown in Figure 1.

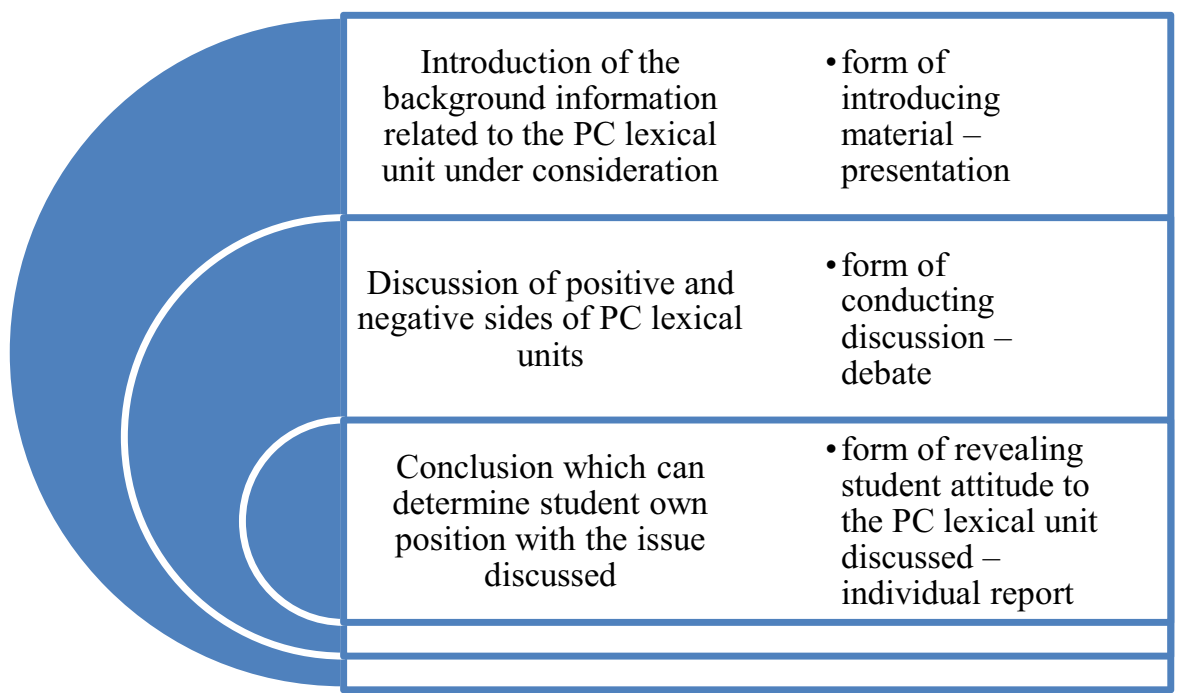

Fig.1. Introduction of the PC lexical unit into the classroom activity

With this in mind, we have identified four main groups of words, which, on the one hand, are relegated as common lexis, and on the other hand, do not fit into the modern cultural and behavioral norms from the perspective of political correctness. When talking about politically correct attitude to this or that category of people, we should bear in mind their individual differences which include their religious and moral beliefs, social conservatism in politics, and unreflective cognitive style [14]. In this respect we share Frank Biermann and Agni 
Kalfagianni's opinion who claim that careful analysis of the aspects connected with policy discourses, community life, and regions on a sustained basis will contribute to our understanding of perceptions and positions by means of which we usually express our opinion [15]. The figure presented below contains the generalized classification of politically correct lexicon we often come across in English classes, which attracts our attention as a lexical layer contributing to broadening the learner's mind.

Group of PC lexicon Objects of PC description

\begin{tabular}{|c|c|}
\hline $\begin{array}{c}\text { Words used to reduce } \\
\text { discriminatory practices }\end{array}$ & Racial and ethnic minorities \\
\hline
\end{tabular}

\begin{tabular}{|c|c|}
\hline $\begin{array}{c}\text { Delicate description of } \\
\text { people with physiological } \\
\text { and psychological } \\
\text { peculiarities }\end{array}$ & Older population \\
\hline $\begin{array}{c}\text { People with physiological and mental } \\
\text { disabilities }\end{array}$ \\
\hline
\end{tabular}

\begin{tabular}{|c|c|}
\hline $\begin{array}{c}\text { Tactful description of } \\
\text { people with low social- } \\
\text { economic status }\end{array}$ & People with low standard of living \\
\hline
\end{tabular}

Diplomatic description of activities undertaken by government bodies

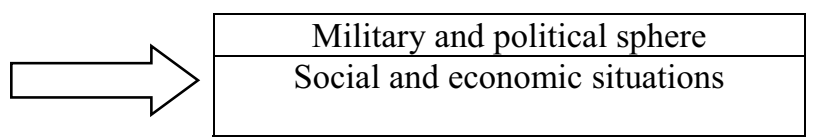

\section{Fig.2. Types of Politically Correct Lexicon}

Let us first take a closer look at the examples, where the language becomes the medium to express our attitude towards various population groups, which is made possible after analyzing the cases of both politically correct and politically incorrect lexicon usage.

\subsection{Politically correct words used to reduce discriminatory practices}

As a matter of fact, we found that racial and ethnic political correctness represents the largest lexical group, which is currently of greatest interest for linguists as well ordinary citizens, since it is human racial origin that is associated with their low or, on the contrary, high social status. For instance, the English phrase $a$ white man means an honest man, a virtuous man, a man of good morals. It stands to reason, that this lexical unit cannot be considered acceptable for human moral qualities description, because it indicates the attitude of a ruling class towards non-white race nations. Nevertheless, such expression appears in one of Rudyard Kipling's poems "The white man's burden", where the author says about so-called colonizers' cultural mission-colonial policy disguise. This expression was often used in the $19^{\text {th }}$ century when white people believed that they had to overcome a lot of difficulties educating less developed people manage their own affairs. A good example includes the term mixed race, which is interpreted as blended racial origin. Political correctness supporters do not consider this expression quite appropriate, since it is heavily focused on parents' racial 
origin, in the meantime, it should be admitted that they do not still have a better version. Another hideous synonym of this expression is the noun half-caste.

Speaking of gender discrimination we should confidently state that the term sexism did originate in the English language. It is the feminist movement that enhances its constant impact in all areas of American society and has provided the basis for so-called "linguistic equality" between different gender groups. Many scientists point out that the English language is full of masculine forms, which is absolutely unacceptable in a democratic environment. In this respect, a vivid example of political correctness in certain lexical unit usage is a few nouns chairman and chairwoman, which demonstrate a changing mental process of a society member towards a woman's role in workflow. To indicate such position in English at present a more neutral noun chairperson is increasingly used that helps to avoid labor gender division. Also, the term flight attendant is currently used instead of the nouns steward and stewardess; actron is replaced with actor or actress, the nouns waitress and waiter are suggested replacing with a gender-neutral waitron. Also a common gender pronoun $s / h e=$ she or he appeared in English for the same reason. Despite that, not all authors share the view that the gender-neutral pronoun $s / h e$ is a panacea for manifestation of discrimination approach to undesirable focus on sex identity being discussed.

\subsection{Delicate description of people with physiological and psychological peculiarities}

The second group touches upon politically correct lexicon, which is based on tactfulness when describing persons different from most people in physiological parameters. In particular, this applies to older persons. Nowadays it is widely believed for some reasons that the English adjective old is associated with such physiological characteristics of older people as diseases, disorientation, feebleness, inability to adequately take stock of the situation, etc. To avoid such preconceived stereotypes, people reaching retirement age are often called the elderly, which is perceived as more respectful towards individuals of this age group. Synonymous expressions are word combinations senior citizen and golden ager. But a logical question arises: how should we treat the title of the famous Hemingway's novel "The Old Man and the Sea" if the adjective old is considered offensive now? It is worth mentioning that such term as ageism is the example of politically incorrect lexicon in English, which, in fact, stands for discrimination towards old people (typically in recruitment process) and gerontophobia, in other words a pathological fear of geriatric meeting. As we see it, to some extent, these quite academic names mask such seamy features as age ignorance of the citizens who have already lived much of the life.

Political correctness with regard to people with disabilities and other physiological characteristics that affect their appearance can also be subsumed under the group described. For example, according to new trends, it is now more appropriate to say hearing impaired instead of deaf mute, because in this case the speaker does not focus on the physical defect the person has. In addition to that, one more example can be given, which relates to physical well-being of some members of society. Now in a series of papers devoted to political correctness in language, one can find an opinion that we should avoid calling handicapped people disabled. According to some analysts it is more correct to use its synonymous expression physically challenged. But due to our work with translators who are taught English for a special purpose we often have to deal with texts from different fields of activity, which allows us to argue that the interpretation of the word disabled is based on the subjective rather than objective opinion. Apparently, this adjective can often be found in medical literature, various books on psychology, social work and many other sources, where it is used as a term and by no means perceived as politically incorrect because it indicates some physiological defects of an individual. When it comes to children with physical or mental 
disabilities it is more appropriate to use the term children with special needs instead of more direct analogues educationally subnormal or backward. In 1975 the law for physically or mentally disabled children Education of All Handicapped Children was adopted in the USA.

\subsection{Tactful description of people with low social-economic status}

The third group includes lexical units that are used to describe people with low socialeconomic status. When studying the ways of choosing politically correct words and expressions towards people with low living standards, we came to conclusion that lexical units of this thematic cluster more frequently appear in mass media (print, audio, online, TV) and science papers.

The next pair of synonymous concepts clearly demonstrates a politically correct approach to a right lexical unit choice and the way to avoid indicating a man's social status. In our opinion, the expression financially challenged, for instance, is less focused on a person's unenviable standard of living than the adjective poor. When describing unpleasant features such synonymous pairs as slums / substandard housing, poor / economically exploited, poor/ in reduced circumstances, unemployed / involuntarily leisured, fired / laid off can also be the examples of politically correct words and phrases.

While examining the options of politically correct address to individuals with low social status, it should be emphasized, that it is quite a larger group of the population, which could involve old people, low-income people, those who have health problems and many others. For instance, the most accepted term denoting socially disadvantaged segments of the population is the collective noun the deprived, which synonym is the term underprivileged. We often come across the example of a "low-status" profession. In particular, with reference to a person's occupation some people consider the job title garbage collector as tactless whereas others do not find it offensive or degrading. Filing clerk is often called data storage specialist, photocopying clerk - reprographics engineer, secretary - executary: execu(tive) + (secre(tary), and post-room worker - office logistics coordinator. Logically, it is appropriate to note here that political correctness in relation to job titles is rather a tribute to fashion, since in this case the harmony of the word plays a more important role than its semantic aspect. Apparently, the prevailing opinion nowadays is that the more intricate name of profession to some extent increases its prestige in society.

\subsection{Diplomatic description of activities undertaken by government bodies}

Under the topic being considered it should be stressed that political correctness originated in the USA, when some steps to overcome discrimination towards black population were taken, and as to political activities it dates back to distant past. For instance, during World War II Hitler declared a massive Jewish holocaust a "final solution to the Jewish problem". In this respect, a war is often called a conflict and the territories where the most violent confrontations take place war zones or hot spots; bombing - air support. As a result, the human losses are undoubtedly estimated among both military troops and civilian population. However, in order to minimize the consequences of such dreadful events English press uses such term as collateral damage. This expression is often delivered when it comes to killed or wounded people as well as civilian facilities destroyed during military action.

\section{Results}

Summing up, we would like to say that political correctness and good manners are not at all interchangeable concepts, and teachers ought to pass on this idea to their students. To achieve 
positive results, it is important to explain to them where political correctness came from and why many people do not share the belief that it helps to eliminate negative stereotyping and discrimination. Being a broad-minded and courteous person (which also applies to politically correct lexicon), one can establish a reasonable dialogue on any subject.

\section{References}

1. S. LMoore-Berg, B. Hameiri, E. Bruneau, The prime psychological suspects of toxic political polarization.Current Opinion in Behavioral Sciences 34, 199-204 (2020)

2. A. Kende, P. Krekó, Xenophobia, prejudice, and right-wing populism in East-Central Europe. Current Opinion in Behavioral Sciences 34, 29-33 (2020)

3. Yu-JuLin, H.-C. Wang, Using enhanced OER videos to facilitate English L2 learners' multicultural competence. Computers \& Education 125, 74-85 (2018)

4. T. Rasskazova, M. Guzikova, A. Green, English language teacher development in a Russian university: Context, problems and implications. Ampersand 4, 1-9 (2017)

5. J. Moss, P. J. O'Connor, The Dark Triad Traits predict authoritarian political correctness and alt-right attitudes. Heliyon 6, e04453 (2020)

6. L. Magnani, Political Correctness between Wise Stoicism and Violent Hypocrisy. Philosophies 1(3), 261-274 (2016)

7. O. Pérez De La Fuente, On Political Correctness. Social Sciences, 8 (2019) doi:10.3390/socsci8100277

8. V. Lichev, M. Hristoskova, Political Correctness - Between Fiction and Social Reality. Philosophies, 2 (2017) doi:10.3390/philosophies2020013

9. B. Klepac Pogrmilovic. "Europe Will Soon Be Lost to Political Correctness". Politička misao 56, (2020) 106-136 doi:10.20901/pm.56.3-4.05

10. A. Dirakis, Political Correctness: Implosion of Politics. Philosophies, 2 (2017) doi:10.3390/philosophies2030018

11. I. C. Mayorga, "Political Correctness" from a "Border Reason": Between Dignity and the Shadow of Exclusion. Philosophies, 2 (2017) doi:10.3390/philosophies2020013

12. A. Sikorski, Translation of Politically Correct Terms and its Reception by Polish Speakers. Tertium, 4 (2020) doi:10.7592/tertium2019.4.2.sikorski,

13. G. Reddy, R. M. van Dam, Food, culture, and identity in multicultural societies: Insights from Singapore. Appetite 149, 104633 (2020)

14. J. Baron, Religion, cognitive style, and rational thinking. Current Opinion in Behavioral Sciences 34, 64-68 (2020)

15. F. Biermann, A. Kalfagianni, Planetary justice: A research framework. Earth System Governance, 100049 (2020) 